Madhuwanthi, H.A.S., Seneviratne, L.D.I.P. and Ganeshu, P., 2019. Developing a pre-task plan for the Sri Lankan construction industry. In: Sandanayake, Y.G., Gunatilake, S. and Waidyasekara, A. (eds). Proceedings of the $8^{\text {th }}$ World Construction Symposium, Colombo, Sri Lanka, 8-10 November 2019, pp. 258 -265. DOI: doi.org/10.31705/WCS.2019.26. Available at: https://2019.ciobwcs.com/papers

\title{
DEVELOPING A PRE-TASK PLAN FOR THE SRI LANKAN CONSTRUCTION INDUSTRY
}

\author{
H.A.S. Madhuwanthi ${ }^{1}$, L.D. Indunil P. Seneviratne ${ }^{2}$ and Pavithra Ganeshu ${ }^{3}$
}

\begin{abstract}
Earlier planning outputs a larger impact against unprecedented changes in construction projects. Pre-task planning (PTP) is a collaborative process that allied prior planning and safety together at the site in the daily basis. PTP allows task-based planning in the sense of associated hazard identification, mitigation and resource allocation. PTP starts with the task definition and moves with job hazard analysis while mandating the scheduling and a pre-job briefing. Therefore, the research was aimed at investigating the use of PTP in the construction projects in Sri Lanka. The study adopted a qualitative research approach. An extensive literature review was conducted and twelve, semistructured interviews involving project managers, safety engineers, site supervisors and site engineers were carried out to investigate the application of PTP in the construction industry, process of PTP, responsible parties to conduct pre-task planning and proposing a suitable format for a pre-task plan. The collected data through the expert interviews were then subjected to a content analysis. Findings confirmed that Construction industry of Sri Lanka is practicing the pre-task planning as safety and resource allocating technique. Further, tasks identification, recognition of potential hazards associated with the tasks, mitigation measures, record, and report were identified as key steps in the process of pre-task planning. Site supervisor was the key responsible party over others in conducting pre-task planning. Primary components that need to be included in the pre-task plan as emphasized by the respondents are; equipment, material, labour, personal protective equipment, work plan and hazards and precautions.
\end{abstract}

Keywords: Definition; Pre-task Planning; Pre-task Plans; Process; Responsible Parties.

\section{INTRODUCTION}

"Planning is a crucial determinate of a project's success" (Hamzeh, et al., 2016, p. 68). According to Gibson and Gebken (2003), many participants consider that the earlier planning is implemented, the impact on project output will be larger. Meanwhile, Amara (2014) highlighted pre-task planning as a collaborative process that allows crew to plan and act together while providing feedback on their specific work tasks on a daily basis. Hinze and Wilson (2000) noted pre-task planning as a high-impact zero accident technique which used for effective safety management in construction projects. Many construction firms need to move in a proactive approach in safety management rather than taking a reactive approach (Kines, et al., 2010). Moreover, Jackson (2014) revealed that pre-task planning encourages crew members to recognize and document the possible hazards and controls to lessen the related risks. Planning ahead of daily work activities is

\footnotetext{
${ }^{1}$ Department of Building Economics, University of Moratuwa, Sri Lanka, hasmadhuwanthi@gmail.com

2 Department of Building Economics, University of Moratuwa, Sri Lanka, indunil@uom.lk

${ }^{3}$ Department of Building Economics, University of Moratuwa, Sri Lanka, sunganesh21@gmail.com
} 
beneficial to the safety performance of the line level workers (Mitropoulos and Cupido, 2009). Hence, Alarcón et al. (2016) recommended pre-task planning as a key practice to conduct a better safety management.

In past researches that have been done in both internationally (Hinze and Wilson, 2000) and in Sri Lankan context (Bhagyani and Kottawatta, 2015) pre-task planning was identified as a major technique used in safety management. But the literature on pre-task planning is less in the Sri Lankan context. Further, for contractors in Sri Lanka, there is a lack of clear and standardized format to be used for pre-task planning. Hence, there is a necessity to recognize the role of pre-task planning in construction project and to develop an appropriate format to use as a pre-task plan.

\section{LITERATURE REVIEW}

\subsection{Pre-Task PlanNing}

Pre-task planning is the final step of construction planning (Ahmadu and Ijigah, 2014). Figure 1 shows the stages of construction planning including the position of pre-task planning in the planning stages.

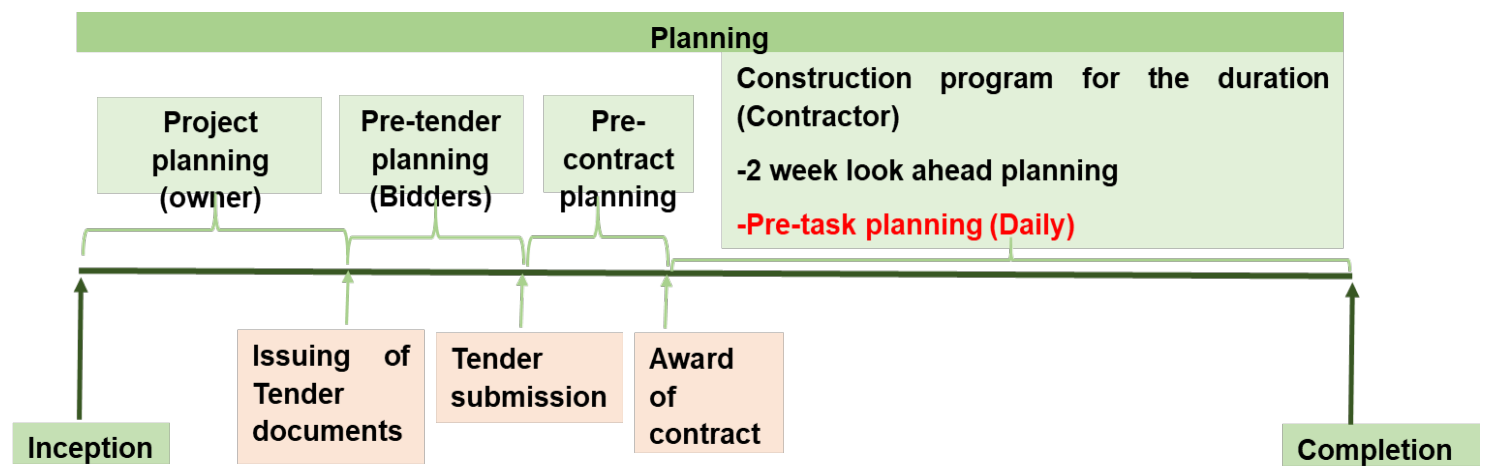

Figure 1: Position of pre-task planning in construction planning stages

The Pre-task planning is dynamic and an active tool for delving into specific hazards, safe work practices, and control over specific and often unique tasks or activities (Jazayeri and Dadi, 2017). According to Thompson and Shea (2016) pre-task planning analysis can be detailed under five components as, define the scope of work, analyse the hazards, develop and implement hazard controls, perform work within hazard control and provide feedback. In the construction industry pre-task safety planning is carrying out to examine work tasks and to identify and manage related hazards (Sacks et al., 2009). Pre-task safety planning includes discussing hazard controls, changing the order of tasks, guards or using personal protective equipment to eliminate and avoid or manage risk (Guo and Yiu, 2015).

\subsubsection{Need of Pre-task Plans in the Sri Lankan Construction Industry}

According to Hinze (2002), in the process of pre-task planning, pre-task plans are documented prior to performing any task which includes procedures to be implemented in terms of safety to identify hazards and means to eliminate or reduce the identified hazards. Pre-task plan have benefits of providing directions and information, including expectations, hazards, work procedures to ensure safety, recent dispatches, changes or updates of weather and immediately collecting the sign-off and buys at the right time before initiating tasks (Thompson and Shea, 2016. Evidently, literature suggests that 
process of pre-task planning and pre-task plans are advantageous in terms of safety performance.

Furthermore, in the study conducted in Sri Lankan context De Silva and Wimalaratne (2012) stated that pre-task plans which is the site level safety and health documentation is vital as a mechanism to eliminate risks. However, the construction industry of Sri Lanka needs more satisfactory efforts to improve the safety (Priyadarshani, et al., 2013). This is due to the neglection of shared duty by project participants towards preventing injuries at the work sites (De Silva and Wimalaratne, 2012). In a way to avoid this, preparing pretask plans provides opportunity to remind and induce workers to involve in the safety planning. So, it is clear that encouraging using pre-task plans would be a possible solution to the construction industry in Sri Lanka to improve safety.

\section{RESEARCH METHODOLOGY}

A research approach can be defined as the process of systematically organizing the research events and collecting data in order to successfully achieve goals and objectives (Thurairajah et al., 2007). Creswell (2013) studied on three types of research approaches as quantitative approach, qualitative and mixed approach. When the purpose of the study is to conduct a narrow survey and the number of involved respondents is large, quantitative approach is more appropriate (Kothari, 2004). According to Fellows and Liu (2003) when a study is designed to conduct in-depth investigations and the number of involved respondents is small, the qualitative approach is appropriate. Moreover, Creswell (2013) avowed that integration of both quantitative and qualitative approaches leads to a mixed approach that involves in collecting both quantitative and qualitative data. Considering the all aforementioned factors, this study followed the qualitative approach. Using the non-probability sampling technique professionals were selected. In order to carry out the study, twelve semi structured interviews were conducted with twelve experts in the construction industry. Respondents with more than 5 years' experience in the construction industry who practice Pre-task planning in construction were selected including project managers, safety engineers, site supervisors and site engineers were considered in collecting data

To develop a pre-task plan format, existing pre-task plans collected from selected organizations were reviewed. Content analysis that provides particular interpretation texts via systematic patterns and a coding was selected to analyse the data. In order to enable content analysis of the study, NVivo software was used as a content analysis technique.

\section{ANALYSIS AND RESEARCH FINDINGS}

\subsection{Practice of Pre-task Planning in SRi Lanka}

Literature findings revealed that in global context, pre-task planning is practiced in the construction industry considering various aspects. However, in the Sri Lankan context, existing literature is not adequately highlighting use of pre-task planning in the local construction industry. However, all the respondents opined that pre-task planning is practiced in the local construction industry. Moreover, all most all the respondents stated that, their current projects are using the pre-task planning. Respondents emphasized that pre-task planning is used in the construction industry as a safety technique as well as a resource-allocating tool. 


\subsubsection{Definition of Pre-task Planning}

Extensive literature review highlighted the non-existence of a standard definition for pretask planning and the need of formulating a definition for the same. Therefore, a definition was derived based on literature as mentioned below and presented to the respondents for their opinions.

"Pre-task planning is a process of defining the work to be completed and the way it is performed while identifying the hazards, risks and their control methods including job hazard analysis, scheduling and a pre job briefing (Sacks et al., 2009; Guo and Yiu, 2015; Thompson and Shea,2016)"

All the respondents endorsed the proposed definition. In summary, respondents emphasized that tool and equipment, hazards, materials, mitigation controls, work force and two-way dialogues are components that needed to be considered in compiling the definition.

Equipment + Material + Work force $=$ Resource allocation

Hazards + Mitigation controls $=$ Job hazard analysis

Two-way dialogues $=$ Pre job briefing

Major addition was the fact "resource allocation" to the definition. Based on the comments, a modified definition for pre-task planning was developed as below.

"Pre-task planning is a process of defining the work to be completed and resource allocation for the task with the way it is performed while identifying the hazards, risks and their control methods including job hazard analysis, scheduling and a pre job briefing"

\subsubsection{Responsible Parties to Conduct Pre-task Planning}

According to the findings site supervisor was identified by most of the respondents as the responsible party over others in conducting pre-task planning. This was similarly argued by Amara (2014) in his study.

\subsubsection{Pre-task Planning Process}

Majority of the respondents stressed tasks identification, recognition of potential hazards associated with the tasks, mitigation measures, record, and report as key steps. All the respondents also emphasized the need of going for a new pre-task plan in a change of working condition. Subsequently, when comparing the existing literature and the practices in the construction industry regarding the process of pre-task planning few differences can be observed.

As in the literature first step of defining the scope of work have been identified by the respondents as task and site conditions identification. Moreover, both the literature and the practice advised on hazard identification, mitigation controls and providing feed backs through recording and reporting. As an addition to the literature, adhering to the method statement and conducting morning meetings are highlighted by the respondents during the interviews. Resources and time required for safe completion of activities was another aspect identified by the experts in the pre-task planning process. Steps, which were detailed by the respondents, and the steps identified in the literature review are demonstrated in Figure 2. 


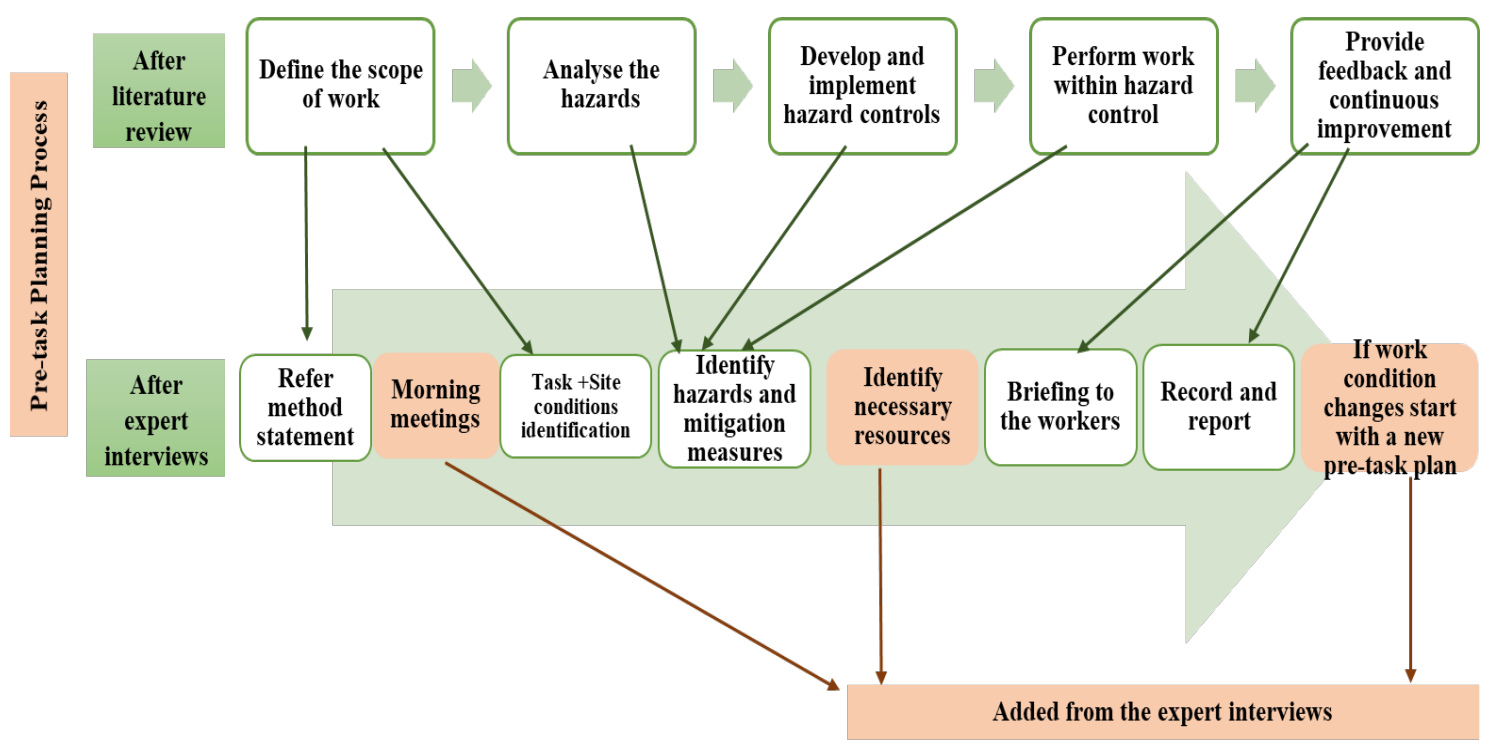

Figure 2: Pre-task planning process

\subsection{Pre-task Plan Formats}

According to the responses of the all the experts, there is no standard format for pre-task plans in Sri Lanka. Figure 3 shows a summary of findings on components in pre-task plans.

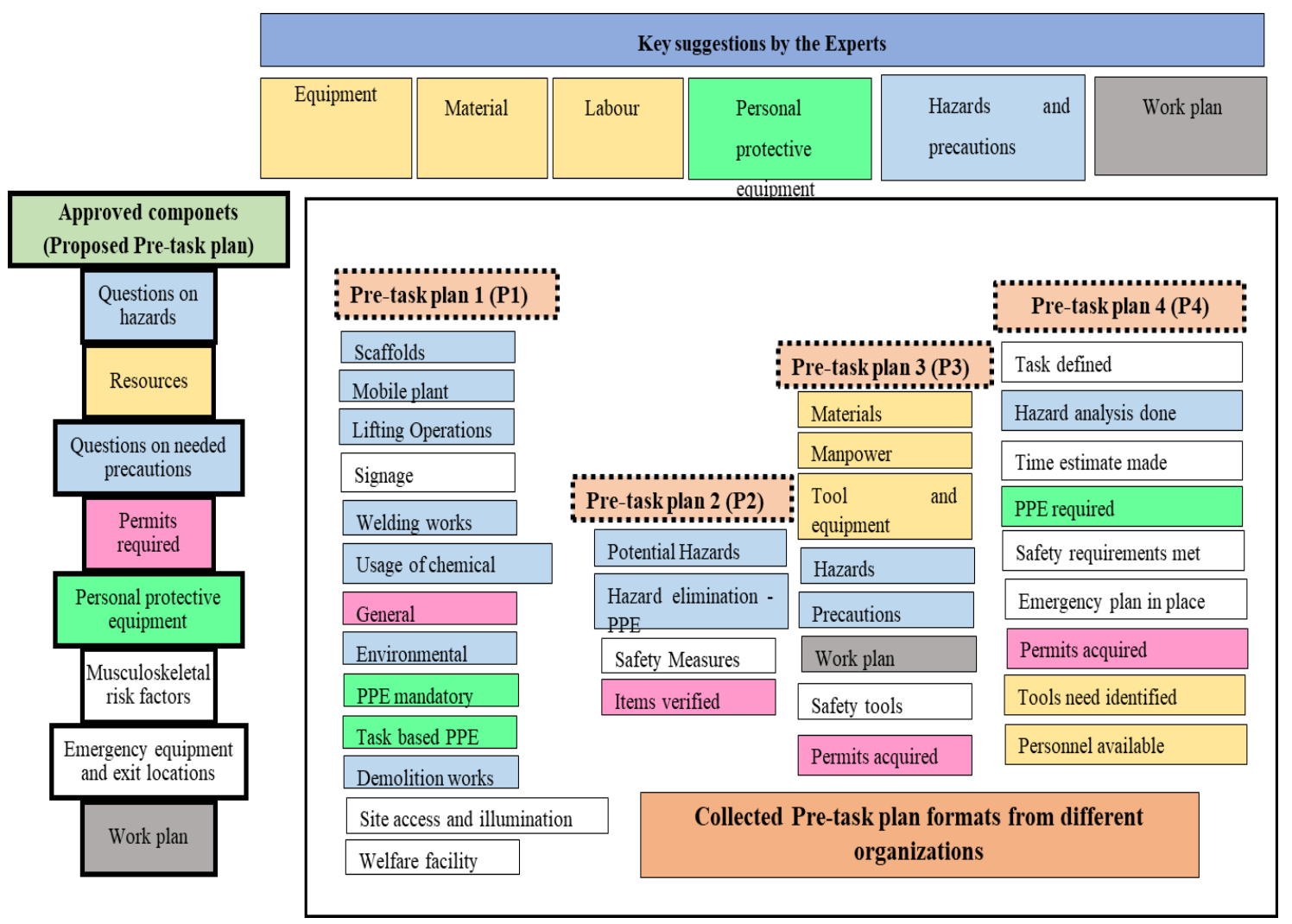

Figure 3: Summary of components of pre-task plans and suggestions of the experts

The main components that should be included in the pre-task plan as emphasized by the respondents are; equipment, material, labour, personal protective equipment, work plan and hazards and precautions. Complying with the suggestions of the experts, the proposed 
pre-task plan also included the components as 'Hazards, Precautions, Personal protective equipment and work plan'. However, collected pre-task plan formats (i.e. P1, P2, P3 and P4) also include aforementioned components. Therefore, it is clear that, those are mandatory components to a pre-task plan. Considering the suggestions of the experts, hazards and precautions were divided into categories according to the categories identified in P1.

When considering the experts suggestions further, additionally 'Materials, Equipment and Labour' also need to be included in the pre-task plan. P3 also highlights the need of 'materials, equipment and labour (manpower)' components while P4 specifies 'labour and equipment' components. However, P1 and P2 keep silent regarding these three components. In the Resources component of the proposed pre-task plan materials, labour and equipment were included and the experts agreed with 'Resources component'. Therefore, being accordance with all the above facts, 'Materials, Equipment and Labour' also have to be included in the pre-task plan. Even though 'Permits required' was not emphasized by the respondents as a component, all the four formats required it as an important component (P1-in General section, P2-Items verified, P3 and P4-Permits acquired).

Moreover, 'musculoskeletal risk factors' and 'Emergency equipment and exit locations' were included in the proposed pre-task plan. Respondents agreed that those two components should have included in a pre-task plan. P1 also identified musculoskeletal risk factors under the category of 'welfare facility'. However, respondents asked to change the word 'musculoskeletal risk factors' and advice to use a simple wording. Therefore, 'personal risk factors' was used instead of 'musculoskeletal risk factors'. Further, P2, P3 and P4 highlighted the Emergency equipment component as safety measures, safety tools and emergency plan respectively. Considering all the above arguments, modified pre-task plan was prepared (Refer Figure 4).

\section{CONCLUSIONS}

Most of the current projects apply pre-task planning as a safety technique in Sri Lankan construction industry. Further, industry uses pre-task planning as a resource-allocating tool. Pre-task plans are the key elements in the pre-task planning process. Pre-task plans are used as checklists to ensure whether safety aspects are appropriately concerned or not in the construction site. Prior to each task supervisor prepared the pre-task plan at the site. Literature identified components of a pre-task plan as hazards, precautions, permits required, resources, work plan, Personal protective equipment, musculoskeletal risk factors, emergency equipment and exit locations. Expert interviews further added environmental, material, labour and equipment components to the pre-task plan. Apart from the aforementioned components in the pre-task plan, general information including company name, location of work, project, task, date, time and the crew size also have to be included. However, pre-task plan to be user-friendly and for ease handling, has to be limited to one-page format. Further, this research proposes a pre-task plan format to industry practitioners to use in their daily works. 


\section{$\underline{\text { Pre-Task Plan }}$}

Company Name:

Date:

\begin{tabular}{|c|c|c|c|c|c|c|c|}
\hline \multirow[t]{2}{*}{ Oate: } & \multicolumn{4}{|c|}{ Time: } & \multicolumn{2}{|c|}{ ype of Cre } & \multirow{2}{*}{ Siz } \\
\hline & \multicolumn{4}{|c|}{ General } & N/A & Yes & \\
\hline \multicolumn{5}{|c|}{ Does every crew member know how to use assigned tools \& equipment? } & & & \\
\hline \multicolumn{5}{|c|}{ Does this task require special training? } & & & \\
\hline \multicolumn{5}{|c|}{ Do you need additional personnel to complete this work? } & & & \\
\hline \multicolumn{5}{|c|}{ Do you need additional materials and tools to do the task? } & & & \\
\hline \multicolumn{5}{|c|}{$\begin{array}{l}\text { Are ladders, Mobile Elevated Work Platform (MEWP), scaffolds or work } \\
\text { platforms needed to perform task? Circle the needed item. }\end{array}$} & & & \\
\hline \multicolumn{5}{|c|}{$\begin{array}{l}\text { Will the task generate important amounts of dust/vibration/ fumes/noise/ } \\
\text { odors }\end{array}$} & & & \\
\hline Permits required & $\mathbf{N} / \mathbf{A}$ & Yes & No & Environmental & N/A & Yes & No \\
\hline \multicolumn{2}{|l|}{ Hot work permit } & & & $\begin{array}{l}\text { Spill kits and dip trays } \\
\text { available }\end{array}$ & & & \\
\hline Confined space Entry & & & & $\begin{array}{l}\text { Chemical proper storage } \\
\text { system }\end{array}$ & & & \\
\hline Excavation permit & & & & $\begin{array}{l}\text { MSDS(Material safety } \\
\text { data sheet) displayed }\end{array}$ & & & \\
\hline Demolition permit & & & & Waste disposable system & & & \\
\hline Work at height & & & & available & & & \\
\hline Road closure permit & & & & Noise control available & & & \\
\hline Critical lift plan & & & & Dust control implemented & & & \\
\hline $\begin{array}{l}\text { Personal Risk } \\
\text { factors }\end{array}$ & $\mathbf{N} / \mathbf{A}$ & Yes & No & 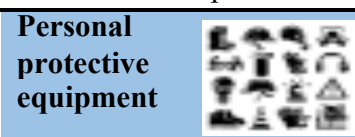 & N/A & Yes & No \\
\hline Forceful exertion & & & & Hard hat & & & \\
\hline Vibration & & & & Overalls & & & \\
\hline Repetitive motion & & & & Safety shoes & & & \\
\hline Static postures & & & & Eye protection & & & \\
\hline Contact stress & & & & Dust masks/Filter masks & & & \\
\hline Shoulders & & & & $\begin{array}{l}\text { Hand gloves/ Rubber } \\
\text { gloves }\end{array}$ & & & \\
\hline Neck & & & & Ear plugs & & & \\
\hline Back & & & & Welding shield & & & \\
\hline Knees & & & & Full face shield & & & \\
\hline Arms & & & & Gum boots & & & \\
\hline $\begin{array}{l}\text { Emergency } \\
\text { equipment }\end{array}$ & $\mathbf{N} / \mathbf{A}$ & Yes & No & Other & N/A & Yes & No \\
\hline Fire extinguishers & & & & Barricades & & & \\
\hline Eye shower & & & & & & & \\
\hline First aid kits & & & & & & & \\
\hline Emergency lights ave & & & & & & & \\
\hline Signage provided & & & & & & & \\
\hline
\end{tabular}

Figure 4: The proposed pre-task plan
Project:

Type of Crew size: 
Alarcón, L. F., Acuña, D., Diethelm, S. and Pellicer, E., 2016. Strategies for improving safety performance in construction firms. Accident Analysis and Prevention, 94, pp.107-118.

Amara, J., 2014. 5 Core Components of Effective Pre-Task Planning. Construction Business Owner Magazine. Available from: http://www.constructionbusinessowner.com/safety/safety/october-2014-5core-components-effective-pre-task-planning-analysis [Accessed 05 December 2017].

Bhagyani, A. A. B. and Kottawatta, H., 2015. Empirical investigation of safety practices in the large scale construction industry in Sri Lanka. Human Resource Management Journal, 3(1), pp.18-32.

Creswell, J., 2013. Research design: Quantitative, qualitative and mixed methods approach. 3 ed. United Kingdom: Sage Publications Ltd.

De Silva, N. and Wimalaratne, P., 2012. OSH management framework for workers at construction sites in Sri Lanka. Engineering, Construction and Architectural Management, 19(4), pp.369-392.

Fellows, R. and Liu, A., 2003. Research methods for construction. 3 ed. Oxford: Blackwell Science.

Gibson, E. and Gebken, R., 2003. Design quality in pre-project planning: Applications of project definition rating index. Building Research and Information, 31(5), pp.346-356.

Guo, B. H. W. and Yiu, T. W., 2015. Developing leading indicators to monitor the safety conditions of construction projects. Journal of Management in Engineering, 32(1), p.04015016.

Hamzeh, F., Zankou, E. and Sakka, F. E., 2016. Removing constraints to make tasks ready in weekly work planning. Creative Construction Conference 2016, pp.68-74.

Hinze, J., 2002. Designing for deconstruction safety. Designing for Deconstruction and Material Reuse, 272.

Hinze, J. and Wilson, G., 2000. Moving toward a zero injury objective. Journal of Construction Engineering and Management, 126(5), pp.399-403.

Jackson, D., 2014. Make Your Pre-job briefing an open dialogue on safety. BIC Magazine. Available from: http://www.bicmagazine.com/departments/health-safety-environmental-subsection/make-your-orejob-biefing-an-open-dialogue-on-safety/ [Accessed 05 December 2017].

Jazayeri, E. and Dadi, G. B., 2017. Construction safety management systems and methods of safety performance measurement: A review. Journal of Safety Engineering, 6(2), pp.15-28.

Kines, P., Andersen, L. P., Spangenberg, S., Mikkelsen, K. L., Dyreborg, J. and Zohar, D., (2010). Improving construction site safety through leader-based verbal safety. Journal of Safety Research, 41(5), pp.399-406.

Kothari, C. R., 2004. Research Methodology; Methods and Techniques. 2 ed. New Delhi: New Age International (Pvt.) Ltd.

Mitropoulos, P. T. and Cupido, G., 2009. The role of production and teamwork practices in construction safety: A cognitive model and an empirical case study. Journal of Safety Research, 40(4), pp.265-275.

Priyadarshani, K., Karunasena, G. and Jayasuriya, S., 2013. Construction Safety Assessment Framework for Developing Countries: A Case Study of Sri Lanka. Journal of construction in Developing Countries, 18(1), pp.33-51.

Sacks, R., Rozenfeld, O. and Rosenfeld, Y., 2009. Spatial and temporal exposure to safety hazards in construction. Journal of Construction Engineering and Management, 135(8), pp.726-736.

Thompson, D. and Shea, J., 2016. Pre-job planning and job hazard analysis. California. Available from: https://www.agc-ca.org/uploadedFiles/Member_Services/SafetyHealth/Safety_Bulletins/SS09_02.pdf [Accessed 03 January 2018].

Thurairajah, N., Haigh, R. and Amaratunga, R., 2007. Leadership in construction partnering projects: Research methodological perspective. pp.35-48. 